\title{
A TERRA SIGILLATA AFRICANA NO CENÁRIO DE ESTUDOS RECENTES: PRODUÇÃO, CIRCULAÇÃO E ESTRUTURAS PORTUÁRIAS
}

\author{
Maria Isabel D'Agostino Fleming ${ }^{1}$
}

Resumo: A Terra Sigillata Africana (ARSW), produzida desde o final do século I d.C., atingiu grande importância a partir dos séculos III-IV d.C. Na versão de vasilhas de mesa e lamparinas de alta qualidade, foi distribuída tanto regionalmente quanto através de bem estabelecidas rotas comerciais na bacia do Mediterrâneo. Estudos recentes sobre sua produção, datação e distribuição apresentam inúmeras discussões e revisões dos principais conjuntos cerâmicos mediterrânicos para resolver problemas de tipologia e cronologia além da atribuição da localização dos centros de produção. Essa linha de investigação leva à interpretação do papel da cerâmica sigillata associada à produção e consumo de produtos de alimentação africanos, como o trigo, o óleo de oliva, o vinho e as salmouras de peixe (salsamenta, garum). Assim, é amplo o cenário das pesquisas que chamam atenção para os limites dos modelos clássicos de estudo da cerâmica africana e realizam revisões acuradas de datação, origem e conteúdo das vasilhas, especialmente com métodos arqueométricos. Neste sentido, novas questões e dificuldades são enfrentadas para explicar os modos de produção e de comercialização da sigillata e das ânforas africanas no Mediterrâneo, tendo como elemento importante o mercado interno africano, com produtos de alimentação de exclusiva circulação regional associados a vasilhas e ânforas com tipologias locais. Tais questões se entrelaçam com e convergem para o problema da estrutura portuária necessária para o escoamento da produção africana. Estudos introdutórios avaliam fluxos dos navios e propõem seus percursos na bacia mediterrânica, entretanto, as pesquisas relevantes nesse contexto revelam a importância do papel dos portos artificiais. Ainda que suas evidências até muito recentemente tenham sido negligenciadas, demonstrou-se que os portos artificiais foram não só a maioria esmagadora como também determinantes no contexto em que se desenvolveram relações entre conectividade e atividades econômicas no Período Romano Tardio. O objetivo deste artigo é oferecer um panorama desta discussão.

PALAVRAS-CHAVE: Cerâmica norte-africana; Produção; Circulação; Estudos arqueométricos; Estruturas portuárias artificiais.

ABSTRACT: The African Terra Sigillata (ARSW), produced since the end of the Ist century A.D., reached great importance from the III $^{\text {th-IVth }}$ centuries A.D. In the version of high quality tableware and lamps, it was distributed both regionally and through well-established trade routes in the Mediterranean basin. Recent studies on production, dating and distribution go through numerous discussions and reviews of the main Mediterranean ceramic assemblies, with

${ }^{1}$ Museu de Arqueologia e Etnologia da Universidade de São Paulo. Laboratório de Arqueologia Romana Provincial (LARP). 
a view to solving typology and chronology problems in addition to the location of production centers. This line of research leads to the interpretation of the role of sigillata ceramics associated with the production and consumption of African food products, such as wheat, olive oil, wine and fish brine (salsamenta, garum). As a result, there is a wide range of researches calling attention to the limits of classical models of African ceramics by offering accurate reviews of dating, origin and content of vessels, especially with archaeometric methods. New issues and difficulties are faced in order to explain the methods of production and commercialization of sigillata and African amphorae in the Mediterranean, having as an important element the African domestic market, with food products of exclusive regional circulation associated with vessels and amphorae with local typologies. These questions intertwine with and converge to the problem of the port structure necessary for the flow of African production. Introductory studies evaluate ship flows and suggest their routes in the Mediterranean basin, however, relevant researches in this context reveal the role of artificial ports. Although this evidence was neglected for a long time, it has been now demonstrated that artificial ports were not only the overwhelming majority but also determinant in the context in which relations between connectivity and economic activities in the Late Roman Period were carried out. The article offers an overview of this debate.

KEYWORDS: North African pottery; Production; Commercialization; Circulation; Archaeometric studies; Artificial port structures.

\section{Introdução}

A Terra Sigillata Africana, também denominada African Red Slip Ware (ARSW), ou seja, cerâmica africana de verniz vermelho, foi uma das mais duradouras cerâmicas finas do Mediterrâneo. Segundo Carandini (1983, p. 146), a cerâmica africana pode ser considerada como a mais difundida de todas as cerâmicas da Antiguidade Clássica. Como de regra, as formas mais comuns não se alteraram do século IV ao VII d.C., sendo que as sigillatas africanas se tornam realmente abundantes no Mediterrâneo Oriental na segunda metade do século IV e começo do V d.C. Este é o momento em que as produções da Tunísia setentrional, especialmente as do baixo vale do Rio Mejerda, atingem a maior parte das regiões sob dominação romana, mesmo as mais recuadas. Mas é também o momento da história em que o Mediterrâneo Oriental está plenamente integrado ao resto da bacia mediterrânica do ponto de vista de seus abastecimentos de cerâmica fina. Da mesma forma como no Mediterrâneo Ocidental, a sigillata africana D torna-se majoritária em muitos sítios da Grécia, Tunísia ou do Levante. 
Esta seria a segunda maior fase de conectividade do Norte da África com a bacia mediterrânica após o período de mudanças importantes do I milênio a.C., resultantes da colonização fenícia, púnica e grega do final do século IX ao VI a.C. No Período Imperial, a conectividade foi construída sobre os primeiros desenvolvimentos coloniais, mas os ultrapassou em larga escala, sendo que na primeira metade do I milênio d.C. surgiram diferentes estratégias econômicas, identidades e padrões de relações sociais à medida em que Roma interagiu com a África de uma maneira muito mais sistemática do que quaisquer poderes externos jamais haviam feito. Foram reconhecidos muitos elementos dessa interação, entre eles o envolvimento extensivo das cidades africanas na annona no comércio marítimo.

Nesse sentido, na questão da difusão e importação das sigillatas africanas associadas ao transporte do trigo, como será visto em maiores detalhes adiante, cabe destacar a importância de escavações sistemáticas de sítios arqueológicos que forneceram perspectivas sobre os trajetos percorridos pelas embarcações, tendo em vista essencialmente a questão prática, estratégica e econômica do fluxo dos navios nos dois sentidos do percurso, de modo a garantir que estivessem sempre carregados (Bonifay e Tchernia, 2012, p. 326; Fleming, 2017). Os resultados são hipóteses sobre os possíveis trajetos executados: a) linhas diretas especialmente para Roma, considerando a importância do tráfico, porém não destinadas ao abastecimento da cidade a partir de Cartago, de acordo com referências a um navio que ligava diretamente Óstia a partir de Hipona (Hippo Regius) (Salvius Iulianus, Digesta, 14.2.6); b) linhas indiretas, tendo em conta o papel desempenhado pelos carregamentos de retorno à África. Neste aspecto, Fentress et al. (2004 apud Bonifay e Tchernia, 2012, p. 326), sugeriram que Roma poderia ter desempenhado um papel de porto-entreposto entre a África e a Sicília, de maneira que uma parte do abastecimento da ilha em ARSW seria assegurada pelos navios de comércio que retornavam de Roma para a África. Ao mesmo tempo, foi sugerido que Alexandria possivelmente tenha sido alimentada de ARSW pelos carregamentos de retorno dos navios da annona (Bes, 2007, p. 190 apud Bonifay e Tchernia, 2012, p. 326).

Uma extensão desse modelo pode ser proposta considerando as condições naturais relativas ao regime dos ventos dominantes que tornam 
impossível o trajeto Alexandria-Roma ao longo da costa da Cirenaica a partir de junho. Neste caso, seria conveniente navegar primeiramente na direção de Chipre a nordeste, chegar à Lícia e, enfim, dar uma guinada para Rodes e o sul de Creta (Arnaud, 2005, p. 13 apud Bonifay e Tchernia, 2012, p. 326).

Assim, um vaso de sigillata africana presente em Creta, dependendo da ocasião, poderia ter viajado primeiramente da África a Roma, depois de Roma a Alexandria e, enfim, de Alexandria para o Mar Egeu, em função das oportunidades das partidas dos navios e do regime sazonal dos ventos (Bonifay e Techernia, 2012, p. 326).

Finalmente, a cabotagem complementa a forma de redistribuição das mercadorias a partir dos portos principais. Ela tem um papel bem conhecido e pode às vezes assegurar a difusão primária dos produtos. Para a ARSW, parece ser bem o caso do sudoeste da Sicília, em virtude da proximidade das costas africanas (Fentress et al., 2004 apud Bonifay e Tchernia, 2012, p. 326). A Numídia, Mauretânia Cesariense, sul da Sardenha e Cirenaica poderiam igualmente, em razão da proximidade, seguir este regime de difusão aleatória das cerâmicas africanas (Bes, 2007 apud Bonifay e Tchernia, 2012, p. 326).

A questão do fluxo e percurso de navios e a difusão e importação das sigillatas africanas na bacia mediterrânica tiveram como referência escavações em sítios arqueológicos de portos naturais bem determinados e conhecidos da literatura. Entretanto, como será tratado no item 3 deste artigo, o aspecto portuário que deu sustentação à produção, circulação e distribuição de itens de produção africana deve ser considerado em um cenário bem mais amplo que inclua as estruturas portuárias artificiais e venha corrigir a negligência desse corpo de evidências, como molhes, cais, recintos e quebra-mares (Stone, 2014). Os resultados desses estudos, ao preencher esta lacuna, trouxeram à luz e puderam comprovar o porte que atingiu a economia africana diante do crescimento significativo no volume total da produção agrícola e artesanal do século I ao IV d.C., sendo que foram atendidas as exigências de padrões econômicos de larga escala.

O boom das importações de sigillatas africanas na segunda metade do século IV e no começo do V é tanto mais impressionante uma vez que é seguido de uma nítida flexão dos aportes a partir da metade do século V. O forte 
aumento da cerâmica sigillata por volta da metade do século IV é tradicionalmente associado à fundação de Constantinopla em 330 (Fulford, 1984, p. 113). Embora a real "fundação" de Constantinopla provavelmente não tenha contribuído para a mudança na distribuição da ASRW em termos diretos, ela determinou uma grande mudança na orientação dos padrões econômicos e outros que se desenvolveram durante os primeiros dois a três séculos a.C. Com a capital do Império localizada mais centralmente e a uma grande distância de Roma, surgiu um novo ponto fulcral em termos administrativos, políticos, militares, diplomáticos e econômicos. Segundo Bes e Poblome (2009, p. 68-69), é nesse contexto que precisa ser colocada uma explicação para a reorientação na distribuição da ASRW durante a segunda metade do século IV d.C. O fenômeno, entretanto, parece ter tido curta duração. Como dito acima, no final do século IV d.C., o volume da sigillata decresceu e continuou até o final do século V d.C., embora com diferentes intensidades. As incursões vândalas dos anos 430 d.C. são frequentemente mencionadas como o fator que causou um declínio na movimentação da ARSW na direção do Mediterrâneo Oriental, embora pareça que ela tenha começado a decrescer algumas décadas antes, o que sugere que os vândalos não devem ter sido o único fator. Para Bes e Poblome (2009, p. 69), talvez os vândalos tenham influenciado a manufatura da ARSW apenas ligeiramente. Ainda que uma quantidade decrescente de ARSW tenha fluído para o Mediterrâneo Oriental, considerando o aspecto distribucional, o que dizer do real volume de produção? Outro ponto a ser considerado é que a manufatura de sigillatas foceias e cipriotas começou no final do século IV d.C. Talvez estas tenham parcialmente substituído a ARSW nos mercados orientais.

Assim, de um modo geral, os sítios orientais fornecem poucas formas atribuíveis à produção africana do período vândalo. Este fenômeno é particularmente evidente para as produções da Tunísia central, que tinham marcado no século III d.C. o verdadeiro ponto de partida das importações de vasilhame africano no Mediterrâneo Oriental e cujas formas tardias características do período vândalo têm uma difusão muito restrita. O Egito, neste contexto, é uma exceção notável, mesmo em relação ao resto da bacia mediterrânica. De todo modo, em proporções variáveis segundo os lugares, as importações de vasilhas africanas parecem recuar ao mesmo tempo no conjunto do Mediterrâneo. A retomada das importações de cerâmica sigillata africana no 
Mediterrâneo Oriental reaparecerá de forma evidente no século VI d.C., quando as produções da Tunísia setentrional são novamente bem atestadas, especialmente as da oficina de Oudhna e as de uma oficina vizinha ainda não identificada.

Além de seu papel como instrumento de datação, e em menor grau, como um veículo para ilustrar o "equilíbrio" de importação-exportação de um depósito, sítio ou área, a ARSW tem recebido atenção crescente de uma variedade de outros ângulos de pesquisa, entre os quais está a convicção de que a cerâmica romana tem o potencial de contribuir para nosso entendimento dos trabalhos "da" economia romana. Afinal de contas, a larga dispersão de um restrito número de vasilhas de mesa com proveniências geralmente bem estabelecidas e seu enquadramento tipo-cronológico, não reflete senão algo de um Mediterrâneo conectado socioeconômica e culturalmente. Em vista da tradição de publicação de cerâmicas de mesa romanas desenvolvidas desde o século 20, amadureceu-se o tempo para uma avaliação dos pontos fortes e fracos, bem como dos paradigmas acadêmicos implícitos (Bes e Poblome, 2009, p. 66).

A despeito de terem sido realizadas importantes pesquisas, não obstante certas exceções, a situação geral para o estudo das vasilhas de mesa no Mediterrâneo Oriental é muito menos desenvolvida do que para a ARSW ocidental. Isto também parece ser o caso da sigillata italiana. A figura da ARSW parece ficar cada vez mais complexa à luz de novas escavações, prospecções, análises arqueométricas e outras evidências. Esta crescente complexidade, no entanto, traz a vantagem de permitir aos estudiosos mapear a infraestrutura de fabricação regional com o desenvolvimento agrícola e artesanal da África Proconsular/Bizacena, que oferece, em teoria, uma melhor compreensão da dispersão da ARSW dentro de um quadro socioeconômico e sociocultural diacrônico. Para além de estabelecer que um objeto tenha viajado entre dois pontos bem estabelecidos, de reconstruir as esferas de produtores, distribuidores, comerciantes, consumidores e as formas em que estes parceiros interagiam, tal mapeamento deveria contribuir para uma melhor compreensão do funcionamento da economia (ou economias?) romana (Bes e Poblome, 2009, p. 67). 
Nesse sentido, houve contribuições significativas de estudos voltados à arqueometria para o conhecimento mais aprofundado da ARSW com análises de petrografia cerâmica que permitiram estabelecer a mesma origem de produção africana de vasilhas encontradas na Líbia, Albânia, França, Antibas e Tunísia, na região de Zitha. Isto levou a considerações sobre a necessidade de um programa ambicioso de prospecção com vistas a estabelecer um inventário global das oficinas africanas na Argélia, Líbia e Tunísia para caracterizar sua produção de um ponto de vista tipológico e petrográfico, bem como identificar as possíveis fontes de matéria prima. As prospecções, contudo, são ainda muito pontuais e desconectadas umas das outras e as escavações extensivas das instalações são quase completamente ausentes (Capelli e Bonifay, 2014, p. 241-242).

Ainda nesse cenário, o Projeto ICRATES tem como objetivos estudar, analisar e explicar padrões de produção, distribuição e consumo de cultura material romana (Bes e Poblome, 2009). A primeira fase do projeto concentrouse na distribuição e consumo de artigos de mesa no Oriente Romano, recolhendo a maior parte dos trabalhos publicados para o Mediterrâneo Oriental em uma base de fragmento por fragmento em um sistema de banco de dados relacional, ou seja, um banco de dados que modela os dados de uma forma que eles sejam percebidos pelo usuário como tabelas, ou, mais formalmente, relações. Para este fim, foram selecionados dados referentes à identificação do material, ao reconhecimento do mesmo (incluindo proveniência) e realizado um quadro tipográfico-textual, de forma que a análise pudesse alcançar a maior precisão possível. A tradição baseada na publicação foi, assim, desconstruída para produzir um banco de dados relacional que agora conta com mais de 25.000 registros, bem como coleta e processamento de dados em progresso. Os dados coletados contêm a maioria dos locais de escavação publicados e regiões de pesquisa e deriva de todos os países modernos do Mediterrâneo oriental (Grécia, Turquia, Síria, Líbano, Israel, Jordânia, Egito e Líbia).

Esses trabalhos críticos mais recentes têm valorizado a contribuição das cerâmicas à história do comércio mediterrânico dos séculos IV ao VII d.C., destacando-se nesse terreno os progressos realizados sobre a parte oriental (Bonifay, 2005). Foram mais bem definidos os locais de fabricação das sigillatas tardias e das ânforas orientais, bem como os detalhes de sua circulação nessas 
duas grandes zonas de troca do Mediterâneo Oriental, que são o Egeu e o Mar Negro, de um lado, e, de outro, o Oriente Próximo (Antioquia, Palestina-Arábia e Egito). Paralelamente, a presença das cerâmicas africanas foi confirmada ao longo de todo o período com um particularismo evidente na difusão dos objetos e modelos. Segundo Bonifay (2007, p. 156), do ano 350 ao 699 d.C., a característica da indústria da cerâmica africana não mudou fundamentalmente, talvez devido às demandas inalteradas. Durante este período, a vitalidade de produção e a tecnologia foram sustentadas por um crescimento econômico e pela mobilidade das oficinas. Entretanto, por volta de 650 d.C., algumas mudanças na tecnologia tornaram-se aparentes, embora fossem lentas na ARSW, ligeiras nas lucernas ou difíceis de explicar na questão da cor ou do material. Em alguns casos, deve-se aceitar certo empobrecimento da tecnologia.

\section{A sigillata africana: novas questões, novos problemas}

Com base nas questões apontadas acima em relação aos estudos sobre a difusão das cerâmicas africanas no Mediterrâneo oriental no Período Imperial Tardio (séculos IV-VII), são três os pontos de apoio do aprofundamento das pesquisas mais recentes: a) o grande crescimento dos aportes de sigillatas africanas na segunda metade do século IV d.C.; b) a desarticulação no transporte das vasilhas finas e das ânforas; c) a influência da cerâmica africana sobre as produções orientais. ${ }^{2}$

Esta linha de investigação introduz a cerâmica sigillata nos parâmetros da produção e consumo de produtos de alimentação africanos, como o trigo, o óleo de oliva, o vinho e as salmouras de peixe, (salsamenta, garum3). Os resultados provenientes de estudos arqueométricos de conteúdo das vasilhas, bem como de revisões cuidadosas de datação, confirmam os limites dos modelos clássicos de estudo da cerâmica africana (Capelli, Bonifay, 2014; Cau et al., 2012). Consequentemente, os modos de produção e de comercialização da sigillata e das ânforas africanas devem ser explicados a partir de novas questões expostas a seguir.

\footnotetext{
2 Entre essas pesquisas despontam as de Michel Bonifay, do Centre Camille Julien (AixMarseille Université/CNRS), que são referência frequente nos debates da área ceramológica e estímulo para novas propostas e diversificação de abordagens críticas dos estudiosos (Bonifay, 2004, 2005, 2007, 2011, 2012, 2013, 2014).

3 Garo (em latim, garum) ou liquamen: condimento feito de sangue, vísceras e de outras partes selecionadas do atum ou da cavala misturadas com peixes pequenos, crustáceos e moluscos esmagados; tudo isto era deixado em salmoura e ao sol durante cerca de dois meses ou então aquecido artificialmente.
} 
2.1 O lugar da oleicultura na produção cerâmica na África e o desenvolvimento geral da economia da província

Os estudos atuais enfrentam os resultados das pesquisas tradicionais que têm como consenso tanto o óleo de oliva como o único conteúdo das ânforas (ou pelo menos o principal produto comercializado) quanto o fato de o mesmo ser o motor da exportação de todas as outras cerâmicas africanas, em especial a sigillata. No momento, as pesquisas históricas e arqueológicas tendem a reduzir a oleicultura em vantagem de outras produções, como as salsamenta (salmouras), o vinho ou a produção maciça do trigo, que viajava em sacos nos porões dos navios (Bonifay, 2011, p. 17). Essa produção maior da África, esquecida um período em proveito da arboricultura, poderia bem constituir o elemento de drenagem da difusão da sigillata africana. Esta ideia foi avançada pelos especialistas Clay (1992, p. 353) e Panella (1993, p. 639 apud Bonifay, 2005, p. 576, nota 72), excepcionalmente para explicar a difusão da sigillata africana no Mediterrâneo Oriental, e hoje talvez conviesse fazer dela um princípio geral. Temos, assim, levantada a questão da desvinculação entre a comercialização da sigillata e os produtos transportados em ânforas, que é uma das questões da síntese da difusão das cerâmicas finas africanas no Mediterrâneo Oriental nos séculos IV-VII d.C.

As ânforas africanas (Fig. 1), com exceção das spatheia (pequenas ânforas, às vezes, quase miniaturas), têm menos sucesso do que a sigillata na região oriental. Esta impressão de raridade é constante durante toda a Antiguidade. Com algumas exceções, as ânforas púnicas não são exportadas para o Oriente antes do século II a.C. As primeiras ânforas africanas de período romano parecem provir da Tripolitana. Ao longo dos séculos II e III d.C., a presença das ânforas africanas clássicas permanece rara (Bonifay, 2005, p. 572). De acordo com Mocanu (2012, p. 326), há pouca possibilidade de que a cerâmica de mesa africana tenha sido adquirida diretamente dos produtores (ceramistas, proprietários das oficinas) e então vendida nos mercados na foz do Danúbio. A teoria pode ser apoiada devido à baixa porcentagem de vasilhas de mesa proveniente do norte da África, cerca de 5 a 10\% de toda a cerâmica descoberta nos sítios romanos de Dobrogea (Cítia). Quanto às ânforas, Mocanu (2012, p. 327) afirma que, usadas para produtos de peixe e óleo de oliva, elas 
foram certificadas em numerosos assentamentos na Scythia Minor, ainda que o número total das mesmas seja muito inferior ao de vasilhas de mesa.

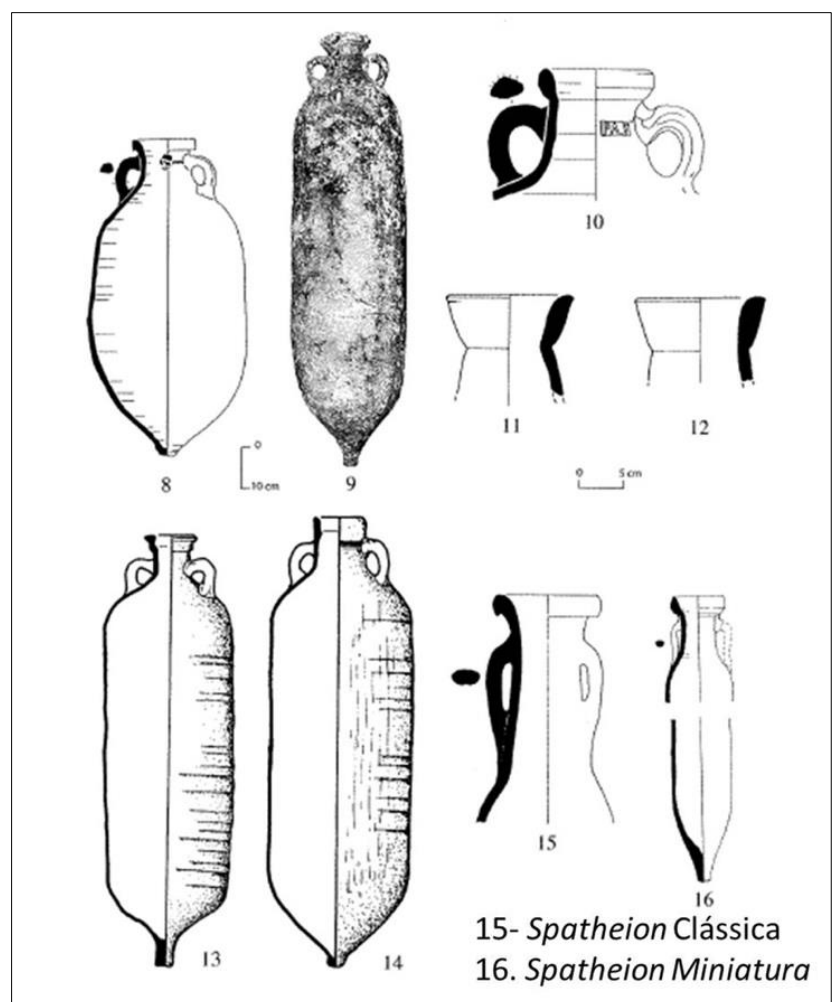

Fig. 1 - Ânforas africanas. Fonte: imagem modificada de Bonifay (2005, fig. 2, p. 573).

Poderíamos esperar que as importações de gêneros africanos seguissem passo a passo a evolução das importações de sigillata africana para a bacia do Egeu. Mas, não foi assim: no século IV as ânforas africanas cilíndricas de dimensão média são sempre muito mal representadas, salvo talvez no Levante. Algumas spatheia aparecem, entretanto, de maneira mais regular na metade do século V. Neste panorama, e, levando em conta a queda das importações de vasilhas na segunda metade do século $\mathrm{V}$ e começo do VI, é surpreendente constatar a presença de ânforas africanas cilíndricas de grandes dimensões em número não negligenciável em vários sítios orientais. Trata-se principalmente de produção do sul da Bizacena e do Cabo Bon, características do período vândalo e bem do início do período bizantino na África. Esses objetos se encontram principalmente no Mar Negro, costas meridionais da Ásia Menor e no Egito (Fig. 2). Enfim, a última particularidade das importações de ânforas 
africanas no Mediterrâneo Oriental consiste na relativa abundância, muitas vezes constatada, das spatheia miniaturas (século VII). Esses aportes, associados à presença contínua, mesmo em fraca quantidade, de ânforas cilíndricas de grandes dimensões dos séculos VI-VII, se encaixam melhor com o que se conhece sobre as importações de vasilhas.

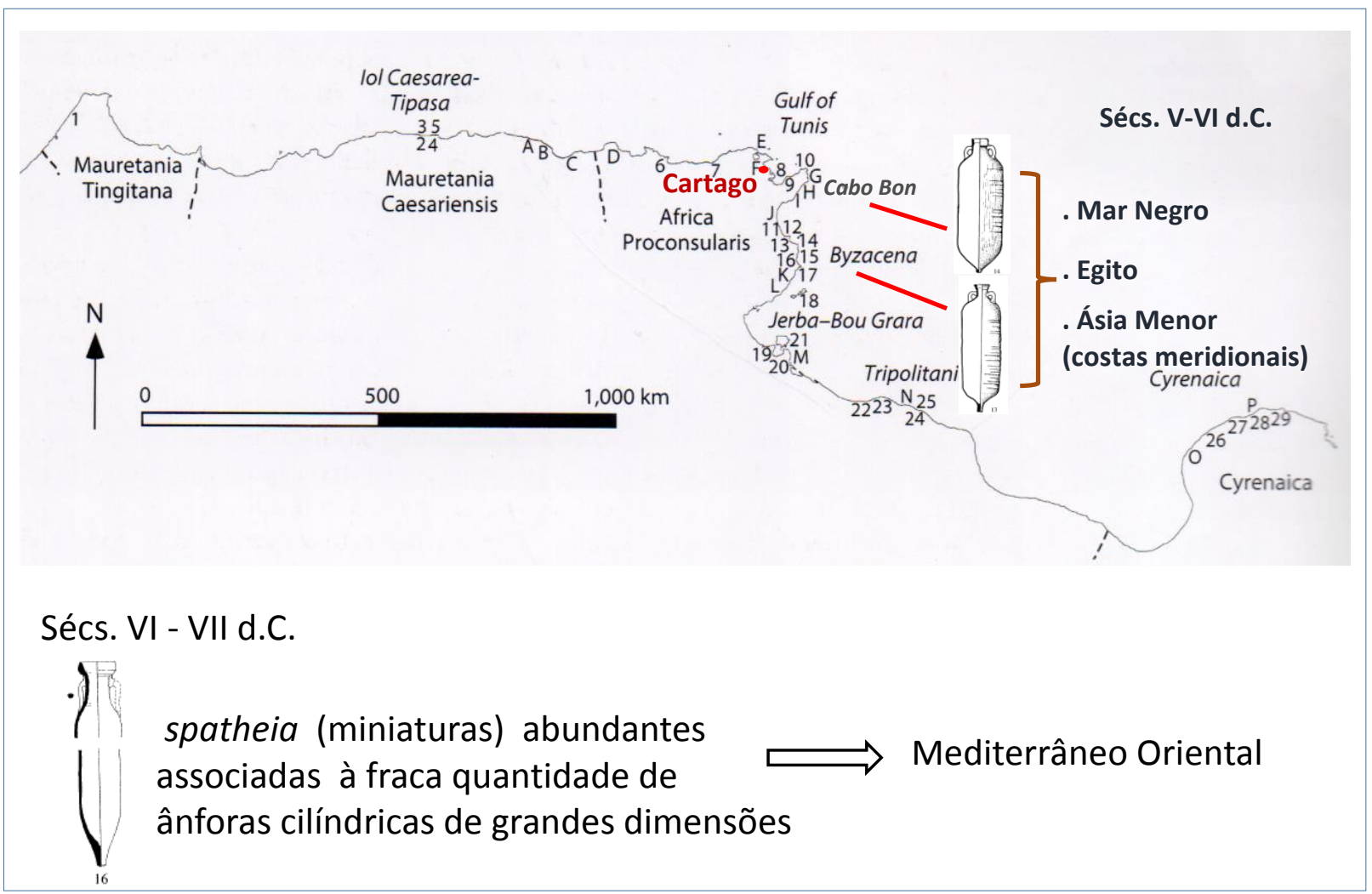

\section{Fig. 2 - Presença de ânforas cilíndricas africanas de grandes dimensões em sítios ocidentais após século $\mathrm{V}$ d.C. Fonte: mapa modificado de Stone (2014, fig. 1, p. 573); dados Bonifay (2005, p. 574).}

Destaca-se que é marcante essa disparidade entre os aportes de vasilhas e de ânforas no Mediterrâneo Oriental, sobretudo durante o crescimento da economia africana do II ao IV século. A partir dessa constatação, surge a pergunta sobre as necessidades reais dos mercados orientais ou sobre os imperativos do sistema anonário e, portanto, sobre a natureza dos alimentos transportados por essas ânforas. A questão do conteúdo das ânforas africanas está longe de ser resolvida, mas é claro que foi talvez dada uma importância grande demais ao óleo. Os únicos recipientes certamente destinados ao transporte do óleo são as ânforas tripolitanas (com exceção do tipo II) e as Africanas I. No Oriente, observa-se que esses objetos são encontrados 
principalmente em períodos mais recuados (tipo Tripolitana II) e/ou em zonas geográficas que produziam pouco ou nada de óleo de oliva (Egito) (Fig. 3). Os demais tipos clássicos de ânforas têm vestígios resinosos e devem ter transportado outros gêneros: salmoura de peixes (Africanas II). Malgrado as indicações frequentemente discordantes, parece provável que as spatheia de pequenas dimensões, tão difundidas no limes danubiano no século VII, eram recipientes para vinho (ou para o garo). A fraca proporção das ânforas africanas no Mediterrâneo Oriental poderia, assim, ser explicada simplesmente por uma fraca demanda de gêneros produzidos na África. Com exceção do Mar Negro e Egito, os recursos locais de óleo eram, com efeito, provavelmente suficientes para evitar apelar à produção africana, como fazia Roma ou a Europa do Norte (Bonifay, 2005, p. 575).

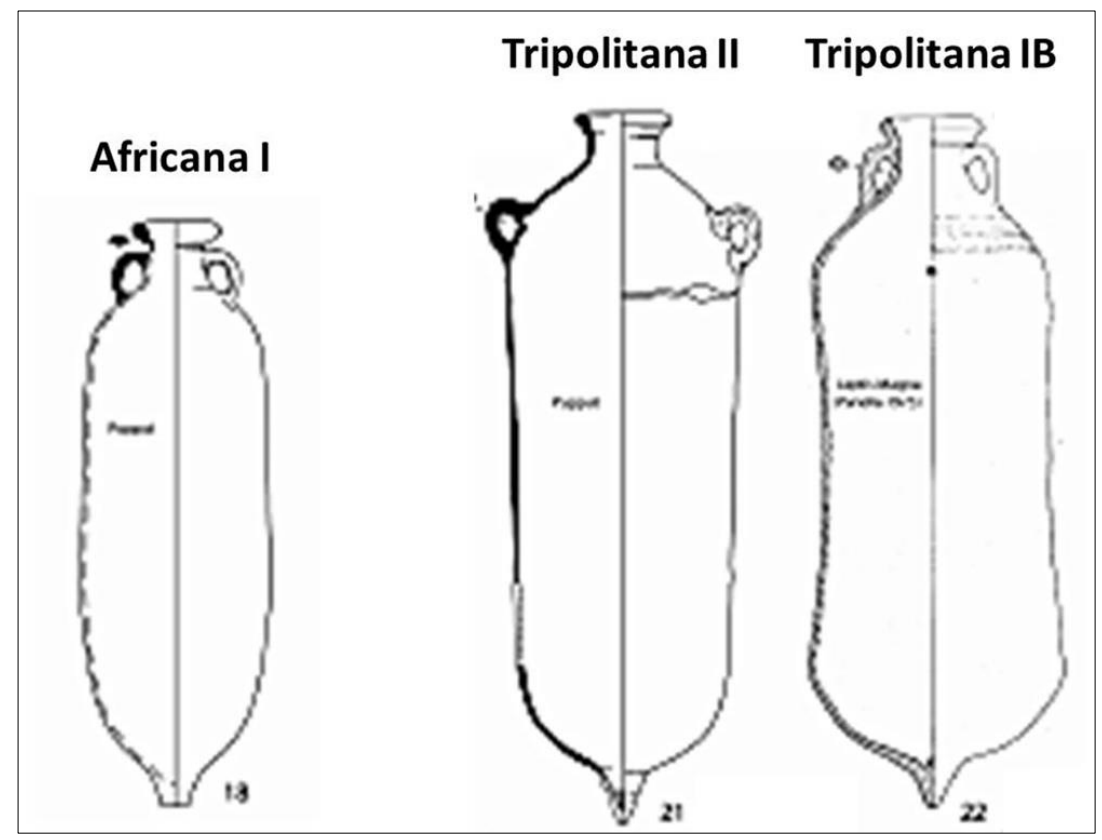

Fig. 3 - Ânforas africanas para transporte de óleo. Fonte: imagem modificada de Bonifay (2011, fig. 2, p. 18).

Voltando à questão anterior: se as cerâmicas sigillatas não viajaram com carregamentos de ânforas, como explicar sua presença e sua abundância, mesmo no século IV, no Mediterrâneo Oriental? Como afirmado acima, vários autores sugeriram a hipótese de que essas vasilhas viajaram com carregamentos de trigo (Clay, 1992, p. 353; Panella, 1993, p. 639). Com efeito, foi observado que a data de criação de oficinas de sigillata africana $\mathrm{D}$ na base do vale do 
Mejerda coincidia com a do crescimento provável das necessidades de trigo do Império, a seguir da fundação de Constantinopla. Mesmo que o trigo do Egito tenha sido desviado de Roma para a nova capital, não é impossível que o trigo africano tenha continuado a alimentar as grandes metrópoles do Oriente, como Tessalônica ou Antioquia, e a drenar, assim, um fluxo de vasilhas de mesa.

Ainda assim, fica uma pergunta: há provas reais em outras localidades do Mediterrâneo de transporte de ânforas e vasilhas de mesa africanas? A parca documentação do Mediterrâneo Ocidental em termos de naufrágios de navios africanos, antes, indica que as ânforas são raramente associadas a carregamentos de vasilhas (Bonifay e Tchernia, 2012, p. 322-324). Se existiu um carregamento complementar de vasilhas nos séculos III-IV, se tratava, então, de vasilhame culinário. Quando se trata de vasilhas de mesa, o naufrágio é de período bem mais tardio. É possível que o transporte em acompanhamento dos cereais tenha sido no Oriente e no Ocidente o modo normal de comercialização das sigillatas africanas, os centros secundários sendo, então, alimentados por ocasião das escalas ou por redistribuição a partir de portos principais.

Esta desarticulação geral entre a comercialização das sigillatas africanas e gêneros transportados em ânforas é ainda sugerida pela situação de cidades da Germânia, como Augst, onde desta vez são as ânforas africanas que, nas devidas proporções, são mais abundantes que as vasilhas de mesa de mesma origem. Da mesma forma, no Oriente, as ânforas (de óleo?) da segunda metade do século $\mathrm{V}$ chegam à Cítia, numa época em que as importações de cerâmica sigillata africana estavam em declínio (Bonifay, 2005, p. 577; Manacu, 2012, p.326-327).

Assim, a conquista vândala na África não teria provocado a parada brutal de todas as relações comerciais com o Oriente, pois um comércio livre parece subsistir (ânforas), principalmente proveniente de regiões afastadas da Cartago vândala, como a Bizacena central e meridional (Figs. 4-5). Mas, com a cessação dos fornecimentos maciços e obrigatórios de trigo, é talvez simplesmente o vetor normal da difusão das vasilhas sigiladas, pequena parcela de negócio (privado?) enxertado sobre o sistema anonário, que teria sido interrompido. 


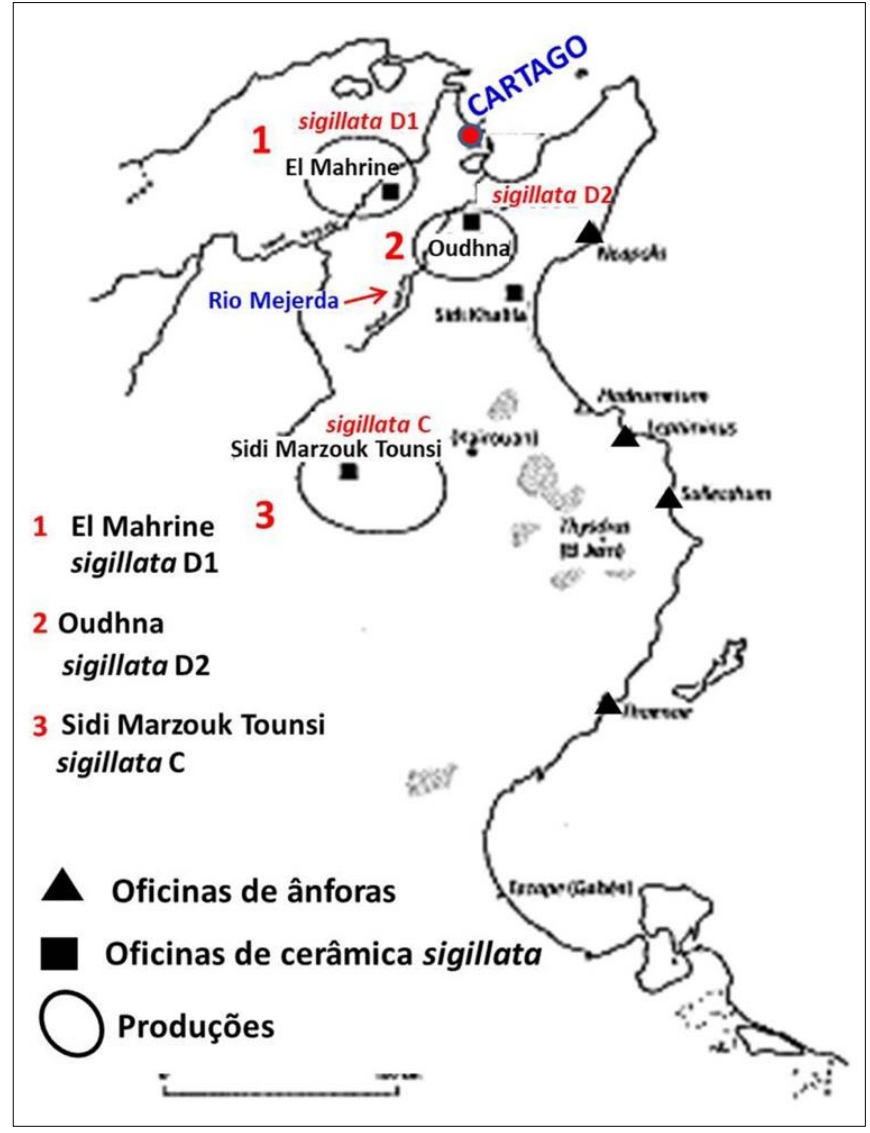

Fig. 4 - Mapa das oficinas de sigillata D1, D2 e C e de ânforas da Bizacena Central e Meridional. Fonte: mapa modificado de Bonifay (2005, fig. 4a, p. 580).

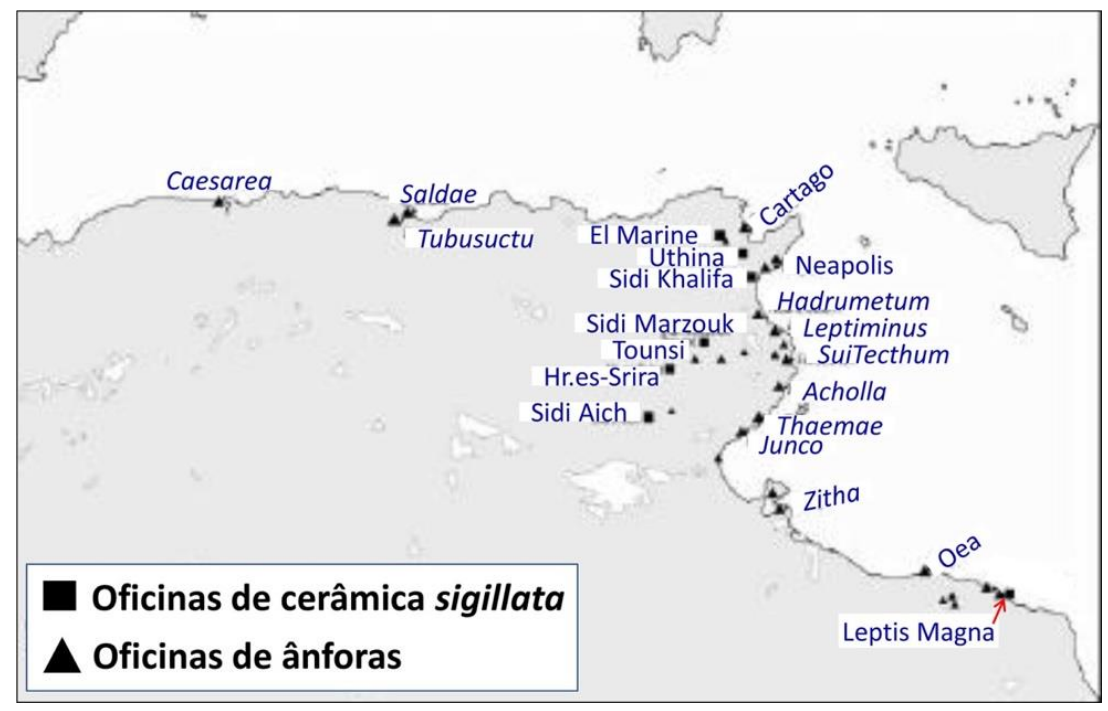

Fig. 5 - Oficinas conhecidas de ânforas e cerâmica sigillata da África romana. Fonte: mapa modificado de Bonifay e Tchernia (2012, fig. 16.1, p. 316). 
2.2 O impacto da criação do reino vândalo sobre a produção e a difusão da cerâmica africana

Agora entramos na segunda questão discutida pelos especialistas e que concerne ao impacto da criação do reino vândalo na difusão e na produção da cerâmica africana. Aqui ainda os estudos históricos e arqueológicos atuais tendem a reavaliar este período de maneira mais pessimista do que os do passado (Bonifay, 2011, p. 25). Na segunda metade do século V, a queda bem atestada na difusão das sigillatas africanas poderia constituir um argumento que valida o modelo proposto acima, pois não há dúvida de que as entregas de trigo anonário cessam a partir de 455. Mas a tendência atual é mais a de reavaliar o papel do comércio privado e o da demanda para explicar uma queda do abastecimento em cerâmica africana bem mais precoce e drástica do que se imaginava, desde o primeiro quarto do século $\mathrm{V}$, especialmente no Mediterrâneo Oriental. Os sinais das transformações do modo de comercialização da cerâmica africana no século $\mathrm{V}$ são evidenciados pelo renascimento súbito das oficinas da Bizacena após mais de um século de hegemonia de Cartago, pelos desembarques não habituais de ânforas de grandes dimensões no mar Negro e pela associação dos carregamentos de ânforas aos de vasilhas cerâmicas (Fig. 6).

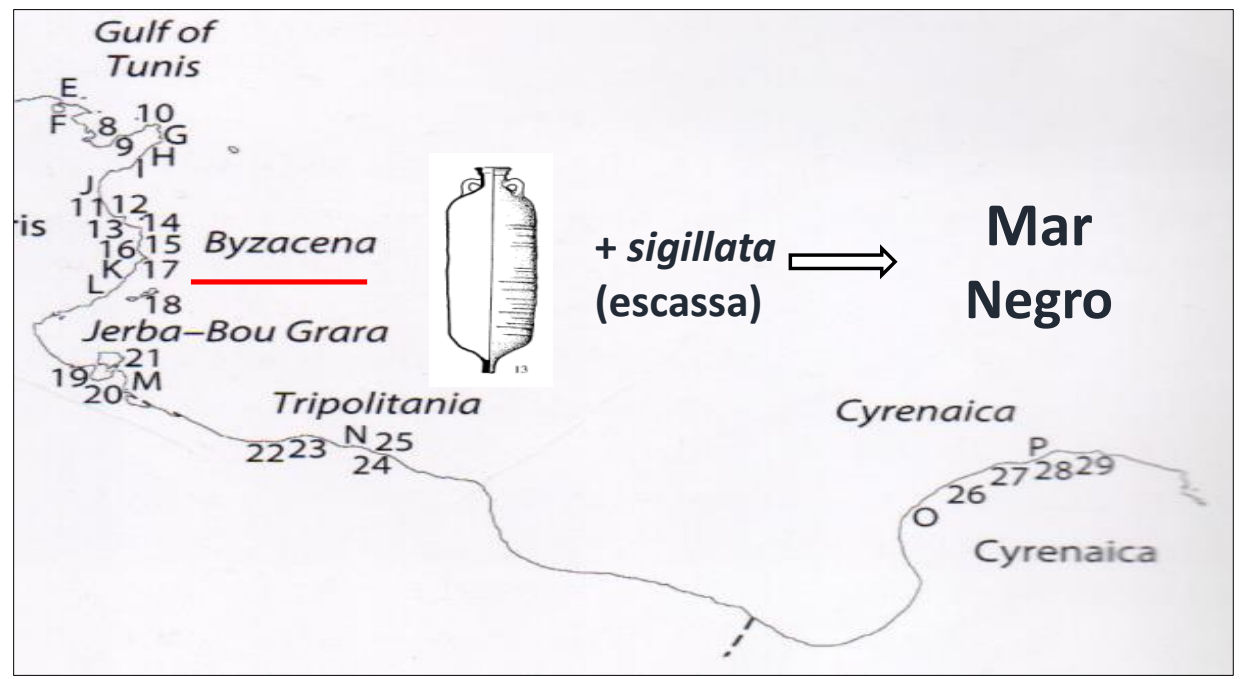

Fig. 6 - Transformação da comercialização da cerâmica africana no século V d.C. Fonte: mapa modificado de Stone (2014, fig. 1, p. 573). 
Outro ponto de vista sobre a questão da produção e distribuição da ARSW e sua relação com a conquista vândala é exposto por Bes e Poblom (2009, p. 64). De acordo com esses autores, para a interpretação econômica da ARSW, os dados coletados emolduraram (tentativamente) um quadro políticohistórico reconhecidamente focalizado nos principais eventos $\mathrm{e}$ desenvolvimentos, como a annona entre a África Proconsular/Bizacena e Roma, a fundação de Constantinopla, a ocupação vândala da África Proconsular/Bizacena e a reconquista de Justiniano. Provavelmente esses eventos moldaram somente algumas linhas das trocas, embora arqueologicamente evidências do Monte Testaccio e de Óstia ecoem a importância crescente da África Proconsular/Bizacena para Roma (e a Tripolitana). Por sua vez, Roma, como os demais grandes portos, agiu como centro de distribuição.

O eixo África Proconsular/Bizacena - Roma/Óstia - Alexandria pode bem ter sido um dos caminhos por onde a ARSW foi dispersa no Mediterrâneo Oriental, mais tarde com Constantinopla como o fator propulsor maior a partir de 330 d.C. D. Pieri (2005, p. 148 apud Bes e Poblome, 2009, p. 73) visualiza uma mudança importante pela qual o trigo egípcio agora fornecia Constantinopla, enquanto o trigo norte-africano era enviado para Roma. Mas, em anos de fome ou fracasso de colheitas, Roma poderia invocar o Egito, bem como outras regiões. Em circunstâncias normais, esta divisão do sistema de fornecimento de trigo seria institucional. Este argumento foi recentemente desafiado por Bonifay, contudo, ele não nega que "logo antes de 330 d.C., o trigo do Egito foi desviado de Roma para alimentar a futura cidade de Constantinopla” (Bonifay, 2003, p. 120 apud Bes e Poblom, 2009, p. 73).

Ao explicar a diminuição substancial da ARSW no Oriente, seguindo a conquista vândala, Bonifay conjectura se a mesma não poderia ter sido enviada ao longo das linhas de abastecimento de trigo africano. Esta premissa baseia-se na escassez de outros produtos cerâmicos africanos, além da ARSW durante a Antiguidade Tardia (exceto a chamada spatheia, que não era incomum no Oriente entre o final do século V e ao longo do VII). A consequência importante desta hipótese é que a África Proconsular/Bizacena serviu ao lado do Egito como fornecedora de uma quantidade considerável de grãos até a conquista vândala, e provavelmente também nos tempos posteriores. O material deve ser 
analisado a partir de diferentes perspectivas, pois o contexto de fabricação (bem como o da dispersão) é crucial para entender o quadro regional de produção, mas também é importante incorporar trajetórias regionais das muitas regiões orientais. A este respeito, estão disponíveis provas sobre o cultivo de culturas agrícolas, padrões diacrônicos de assentamentos rurais e urbanos e o quadro artesanal da produção de ARSW, ânforas, utensílios de cozinha e lucernas todos esses registros são objeto de considerável atenção para Bonifay.

No que diz respeito à dispersão, é claro que metodologias melhoradas, como identificação do material e quantificação completa, têm muito a contribuir. Além disso, precisamos aceitar a complexidade dos padrões de intercâmbio intra e inter-regional e o fato de que pode ser possível reconstruílos e explicá-los apenas até certo nível. Os esforços multifacetados que ultrapassam o alcance tradicional da arqueologia também podem contribuir para a compreensão da posição econômica da África Proconsular/Bizacena na Antiguidade Tardia (Bes e Poblome, 2009, p.73)

Com base neste rápido exame dos dados atualmente disponíveis, parece que o Mediterrâneo Oriental não constitui um exemplo único na difusão das cerâmicas africanas no mundo da Antiguidade Tardia. Esta região passa pelos mesmos ritmos do Mediterrâneo Ocidental, às vezes de forma atenuada, às vezes exacerbada, mas estes são reflexos das condições mutáveis da produção e da difusão de gêneros africanos. Mais ainda, mesmo que fosse uma figura de paradoxo a dissociação, observada no Oriente, entre as ânforas africanas e as vasilhas finas, entre essas incluindo as lucernas, ela reforça o modelo de difusão aplicável ao conjunto da bacia mediterrânica: o trigo da África poderia ter sido o vetor principal da exportação das cerâmicas sigiladas (Bonifay, 2005, p. 579).

Por outro lado, a partir do ponto de vista das regiões exportadoras, pode-se observar um jogo complexo de equilíbrio entre as diferentes zonas da África romana, no qual o papel de Cartago não aparece forçosamente exclusivo. Vimos que a região produtora, que pode ser a mais precocemente atestada no Oriente, era a Tripolitana (exportações de óleo para o Egito e Creta). A seguir é Bizacena que está na origem do verdadeiro avanço da presença comercial africana no Mediterrâneo Oriental no século III d.C., com o óleo no Egito e provavelmente as salmouras de peixes (Grécia, Levante e em Creta), mas, sobretudo, com aportes significativos de cerâmica sigillata africana de tipo C 
(cuja difusão é geral), talvez associados à exportação de trigo. A Bizacena desempenhará igualmente um papel importante na segunda metade do século $\mathrm{V}$, talvez sendo a única região do reino vândalo da África a manter contatos regulares com o Império do Oriente, pela exportação do óleo (Mar Negro e Egito) e quantidades geralmente muito fracas de cerâmicas sigillatas e lucernas (Stone, 2014, p. 572 e Tabela 5, p. 591). Enfim, a região de Cartago está provavelmente nas origens das exportações maciças de trigo, talvez no quadro de medidas fiscais, que poderiam testemunhar o boom das importações de sigillatas africanas D no século IV e sua retomada no VI.

Restaria, enfim, afinar a carta de atribuições de cerâmicas no Mediterrâneo tendo em conta não apenas os dados cronológicos e a origem precisa desses objetos, mas igualmente as condições locais da produção do mercado (Bonifay, 2005, p. 581).

\subsection{O verdadeiro consumo da produção africana de alimentos}

Após ter sido considerado por muito tempo pelos estudiosos que esta produção se dirigia exclusivamente para a satisfação das necessidades das outras províncias (talvez numa atitude inconscientemente neocolonial), percebe-se hoje que ela mirava essencialmente (ou mais fortemente?) o mercado local (Bonifay, 2011, p. 25). Com efeito, as pesquisas realizadas no território africano mostram toda a dificuldade de explorar a cerâmica das escavações e das prospecções com as tipologias elaboradas nos grandes sítios mediterrânicos não africanos (Cau et al. 2013) e revelam, dia após dia, faces inteiras da produção de vasilhas e de ânforas que foram reservadas para uma estrita difusão regional (Figs. 7-9).

Os estudos dos padrões de consumo nas regiões costeiras da África, comparados com os das regiões do interior, mostram que lidar com as cerâmicas finas das regiões internas da África é muito desconcertante. Muito poucas produções "clássicas" são atestadas, enquanto as tipologias regionais são ainda embrionárias. Por exemplo, a sigillata da região norte da Tunísia é quase que totalmente ausente dos sítios internos. Até agora nenhuma forma bizantina do século VII foi registrada nas regiões interioranas. 
1 El Mahrine

$$
4
$$

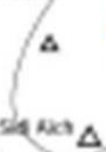

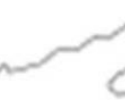

1

El Mahrine

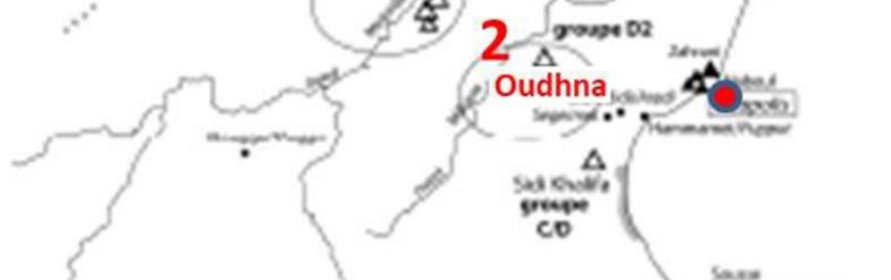

Sidi Marzouk Tounsi taver

${ }_{3}$

(a)

$\triangle$ Djilma mos

5

2 Oudhna

3 Sidi Marzouk Tounsi

4 Henchir es-Srira

5 Djilma

$\Delta$ Oficinas de ânforas

Neápolis: conhecida pelos timbres

$\Delta$ Oficinas de cerâmica sigillata

Neápolis: cidade antiga

(Kairouan): cidade atual

Produções continentais

Fig. 7 - Distribuição africana continental de ânforas e cerâmica sigillata. Fonte: mapa modificado de Bonifay (2011, fig. 4, p. 26). 


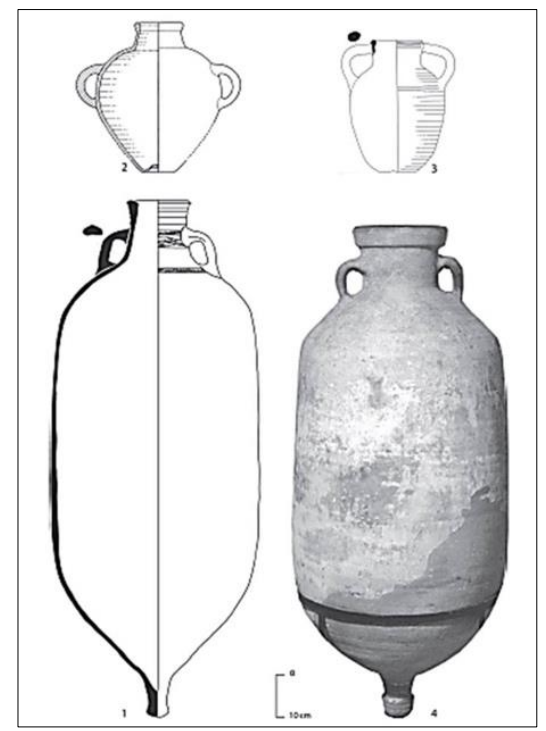

Fig. 8 - Ânforas africanas de distribuição continental. Fonte: imagem modificada de Bonifay (2013, fig. 1, p. 538).

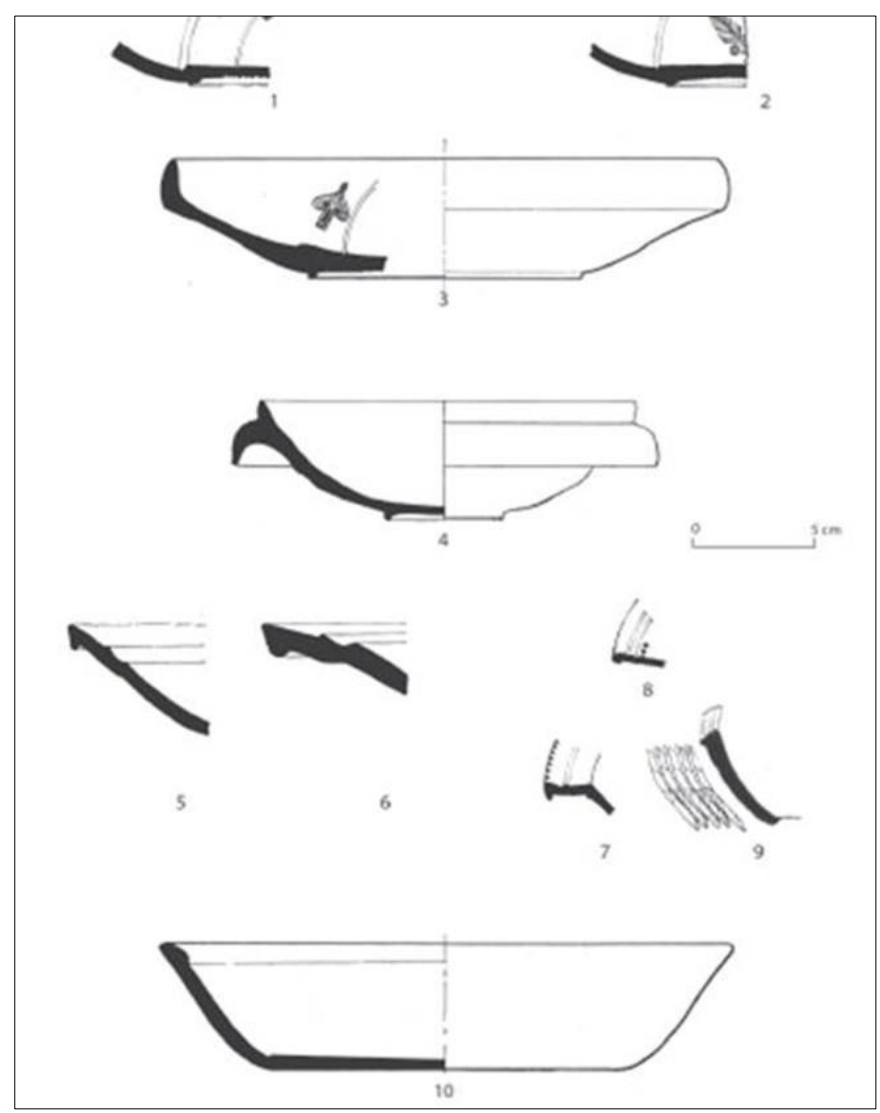

Fig. 9 - Cerâmica sigillata do interior africano. Fonte: imagem modificada de Bonifay (2013, fig. 2, p. 543). 
Como conclui Bonifay (2013, p. 557):

Parece que na Antiguidade Tardia o padrão de consumo mediterrânico era restrito a uma faixa verdadeiramente estreita da costa africana, com exceção de umas poucas e remotas cidades importantes. Vale destacar que as importações de além-mar para a África consistiam predominantemente de vinho, com apenas pouco óleo e muito poucos produtos de peixe ou cerâmicas de mesa.

O mercado local era forte em toda a África, não só nas regiões do interior, mas também ao longo da costa, provavelmente devido à produção onipresente dos mesmos produtos alimentares nessas últimas áreas; isto é, os três principais alimentos, geralmente comercializados no Mediterrâneo romano: óleo, vinho e produtos de peixe. Com toda a probabilidade, a maioria das pequenas cidades africanas também tinha produção e mercados locais igualmente fortes. Como já afirmado por C. Wickham, o que está em jogo na África da Antiguidade Tardia não é a existência de um mercado mediterrânico versus um mercado local, mas, em vez disso, a possibilidade (ou não) do comércio regional interprovincial ou "intra-diocesano". Naturalmente, não há dúvida de que esse comércio existia ao longo do litoral, principalmente de Zeugitana e Bizacena, a leste e a oeste.

Enfim, ainda segundo estudos recentes, na apreciação da produção e da difusão da cerâmica africana, resta fazer desaparecer uma última barreira psicológica, a da conquista árabe. O exemplo da Síria e do Egito, conquistados pelo Islão mais de meio século antes de Cartago, serve como referência. Foi demonstrado nessas regiões que a cerâmica dos primeiros períodos de dominação árabe foi muito pouco diferente daquela dos últimos tempos do período bizantino. Inclusive, as descobertas de ânforas sírio-palestinas e egípcias nos contextos ocidentais datadas do final do século VII provam que a dominação omeyyade (661-750 d.C.) não entravou em nada o comércio, compreendido o do vinho em direção das terras cristãs. Segundo Bonifay (2011, p. 30), para a África, as pesquisas recentes tanto nos lugares de produção como nos sítios consumidores do norte do Mediterrâneo enviam sinais similares: é preciso, sem dúvida, se curvar a esta evidência de que o comércio africano não cessa necessariamente com a queda de Cartago. 
3 A estrutura portuária do norte da África: o papel dos portos artificiais

As pesquisas sobre o fluxo de mercadorias provenientes de exportações norte-africanas no Período Imperial Romano Tardio, em sua quase totalidade, referem-se tanto aos gêneros alimentícios quanto aos recipientes e vasilhas utilizados para transportá-los ou servi-los às mesas. Enfim, das ânforas em seus mais diversos tipos à ARSW, muitas possibilidades de estudos são propostas pelos especialistas, com destaque para aqueles com métodos arqueométricos: para estabelecer tipologias mais precisas; locais de produção ou proveniência, com uso da petrografia cerâmica para definir a composição das pastas cerâmicas; conteúdo dos recipientes, com análises químicas dos vestígios impregnados no vasilhame etc.

À medida que cresceu a complexidade da ARSW a partir das novas linhas de pesquisa acima analisadas, outros estudos de cunho econômico permitiram mapear a infraestrutura de fabricação regional com base no desenvolvimento agrícola e artesanal da África Proconsular/Bizacena. Esta região oferece uma melhor compreensão da dispersão da ARSW dentro de um quadro socioeconômico e sociocultural diacrônico e, consequentemente, uma melhor compreensão do funcionamento da economia (ou economias?) romana (Bes e Poblome, 2009, p. 67).

Com ênfase nos aspectos econômicos do cenário norte-africano do Período Romano Tardio, os estudos da circulação e distribuição da cerâmica sigillata africana negligenciaram um corpo essencial de evidências até muito recentemente: as estruturas portuárias artificiais, tais como molhes, cais, recintos, quebra-mares. Segundo Stone (2014, p. 565), foram identificadas 29 estruturas definitivas e dezesseis possíveis entre a Cirenaica e a Mauritânia Tingitana, com datação entre o início do século IV e ao longo do século VI d.C. (Fig. 10). 


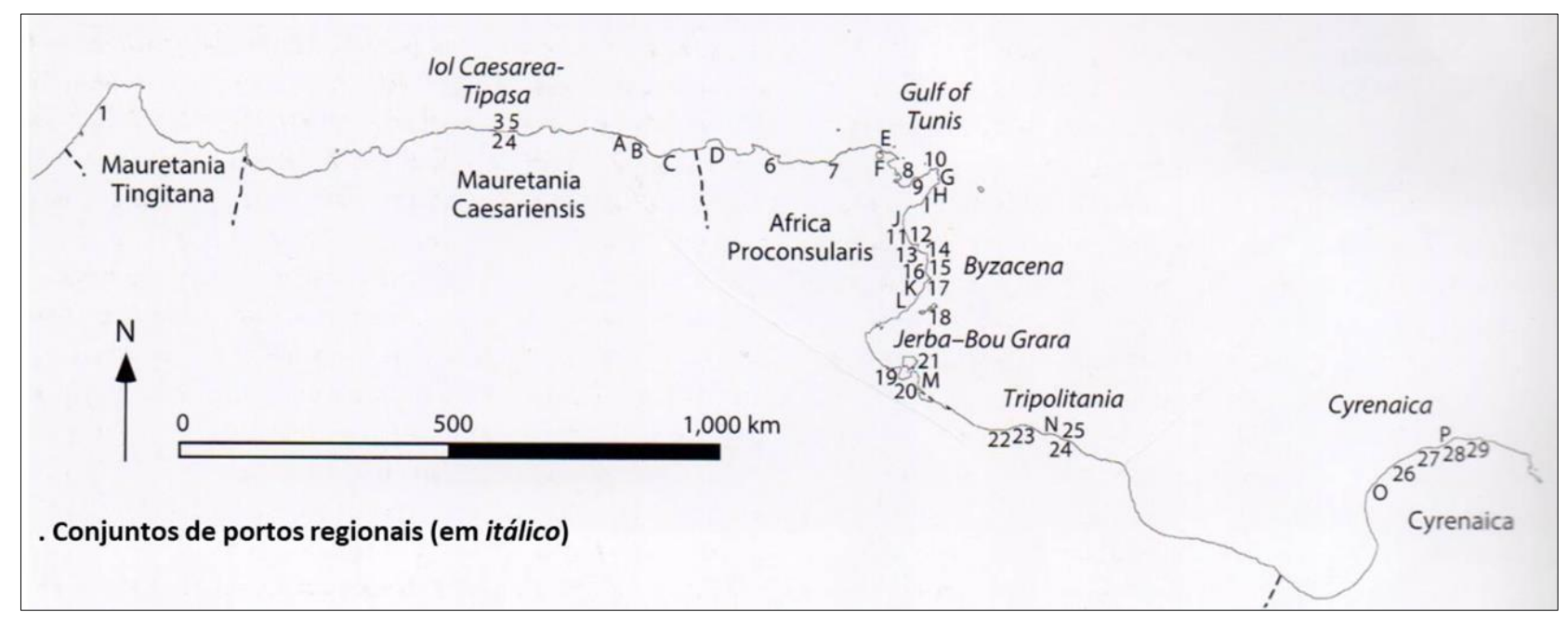

Fig. 10 - Locais dos portos com estruturas artificiais do Norte da África (séculos

IV-VI d.C.): 1, Lixus; 2, Iol Caesarea; 3, Ras el Meskouta; 4, Thalefsa; 5, Tipasa; 6, Hippo

Regius; 7, Thabraca; 8, Cartago; 9, Carpis; 10, Misua; 11, Hadrumetum; 12, Ruspina; 13, Leptiminus; 14, Thapsus; 15, Mahdia; 16, Sullecthum; 17, Acholla; 18, Cercina; 19, Gigthis; 20 , Ras Segala; 21, Meninx; 22, Sabratha; 23, Oea; 24, Homs; 25, Lepcis Magna; 26, Taucheira; 27,

Ptolemais; 28, Phycus; 29, Apollonia; $A$, Iomnium; $B$, Saldae; $C$, Musluvium; $D$, Rusicade / Stora; $E$, Hippo Diarrhytus; $F$, Utica; $G$, Clipea; $H$, Curubis; $I$, Neapolis; $J$, Horrea Caelia; $K$, Thaenae; $L$, Macomades; $M$, Zarzis; $N$, Villa dell'Odeon Maritima; $O$, Euesperides / Berenice; $P$, Haniya. Fonte: mapa modificado de Stone (2014, fig. 1, p. 573).

O foco nos portos africanos situa-se num período em que a economia emergiu como um dos subcampos de pesquisa mais ativos do norte da África do Período Romano. Nesse contexto, as publicações de evidências primárias e sínteses de grande quantidade de conjunto de dados foram realizadas regularmente nos últimos 30 anos, com indicação de um crescimento significativo no volume total da produção agrícola e artesanal do século I ao IV d.C., sendo uma das causas mais prováveis o crescimento populacional nas províncias africanas, demandas de Roma ampliadas e maiores possibilidades de exportação (Bonifay, 2003, 2004, 2005, 2007, 2011, 2013, 2014; Bonifay e Tchernia, 2012; Bonifay e Capelli, 2013; Capelli e Bonifay, 2014; Bes e Poblomo, 2009; Humphrey, 2009). Não obstante esse cenário, uma área relacionada em que nenhuma evidência primária tenha sido apontada ou alguma síntese desenvolvida é a dos antigos portos. Segundo Stone (2014, p. 566), 
Nossa compreensão sobre os portos tem sido dificultada por um foco em textos antigos de curto alcance e pela falta de trabalho de campo arqueológico nas estruturas portuárias. Essas limitações dificultaram compreender a escala de investimentos nas instalações portuárias.

Com efeito, este é um aspecto extremamente relevante e que, talvez, não tenha sido muito explorado devido às imagens negativas trazidas por autores antigos do período entre 50 e 80 d.C., como Salústio (Iug. 17.5), Estrabão (17.3.20), Plínio o Velho (HN 5) e Pompônio Mela (1.30-2) que descreviam a costa africana como naturalmente sem portos. Entre os autores modernos que tiveram mais influência para a cristalização desta imagem negativa desponta J. Rougé (1996, p. 133-134, 14445 apud Stone, 2014, p. 567). Este autor faz uma síntese em que descreve a costa norte-africana naturalmente sem portos, com pequenos portos desorganizados e aparência geral pobre. A falta de inscrições em portos levou Rougé a concluir de mínimo valor econômico os portos da Mauritânia Cesariense e África Proconsular. Várias outras razões para este descompasso entre os dados econômicos do norte da África e o conhecimento de uma estrutura portuária condizente e responsável pela escoação dos produtos para os mercados do Mediterrâneo são apontadas por Stone (2014, p. 567), sobretudo a concentração das escavações arqueológicas em Apolônia, Cartago e Lepcis Magna, evitando portos menos proeminentes. Por último, acrescenta “... talvez a mais insidiosa [razão] tenha sido a relutância por parte dos estudiosos modernos em atribuir sofisticação ou riqueza aos habitantes da África do Norte antiga”.

\subsection{Vantagens das estruturas portuárias artificiais: critérios e pontos a considerar}

Tendo em vista o papel dos portos artificiais para a economia do norte da África, um dos critérios de estudo é confrontá-los com os portos naturais e estabelecer os pontos que indicam sua superioridade. O comprimento dos cais em comparação à área portuária revela a medida do comprimento de todas as estruturas ao longo das quais as embarcações poderiam aportar. Este dado fornece a capacidade do porto de atender às necessidades de escoamento dos produtos da região (Stone, 2014, p. 582).

Entre os pontos a considerar neste confronto está o fato de que os portos naturais desempenharam um papel menor no comércio marítimo, sendo significativos apenas em uma escala local. Portos artificiais são a fonte mais 
confiável de informação sobre padrões econômicos de larga escala, pois permitem comparar tamanhos, formas e capacidade de atracação dos portos para produzir sínteses de outros aspectos mais bem conhecidos da economia africana (Stone, 2014, p. 594). Entre as questões sobre a razão de terem sido construídos portos artificiais nos séculos I ao III d.C., este autor elenca: as facilidades de carga e descarga dos navios atracados ao longo do cais ou molhe em comparação ao transporte por barcos até o navio atracado na costa; o uso de rampas em superfície sólida; evitar manobras; a proteção dos ventos e a segurança de mais navios em um porto. A explicação básica de sua construção é a forte relação entre essas estruturas e a exportação de excedentes agrícolas e marítimos.

Contrariamente ao que afirmam os estudos tradicionais, com destaque para o de Rougé (1966), segundo o qual seriam desnecessários portos na Bizacena e Jerba-Bou Grara, tendo em vista que Cartago atendia às necessidades de uma ampla região do norte da África Proconsular (Zeugtana), a maior porcentagem do comprimento total de cais portuários no norte da África por província concentra-se na Bizacena, onde havia muitos pontos de distribuição para os excedentes agrícolas e marítimos da África Proconsular (Stone, 2014, p. 584) (Figs. 11-12).

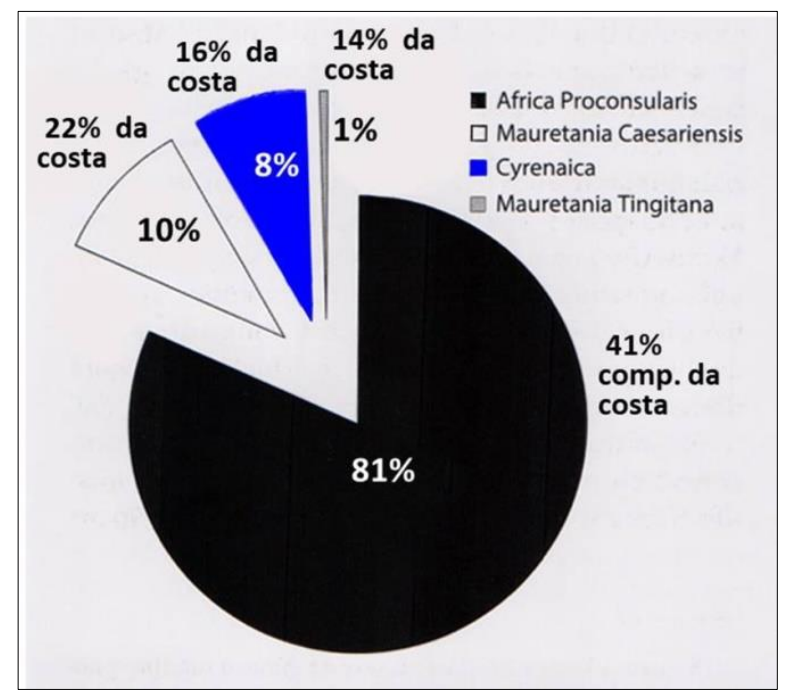

Fig. 11 - Porcentagem do comprimento total de cais na África do Norte por província. Fonte: gráfico modificado de Stone (2014, fig. 7, p. 583). 


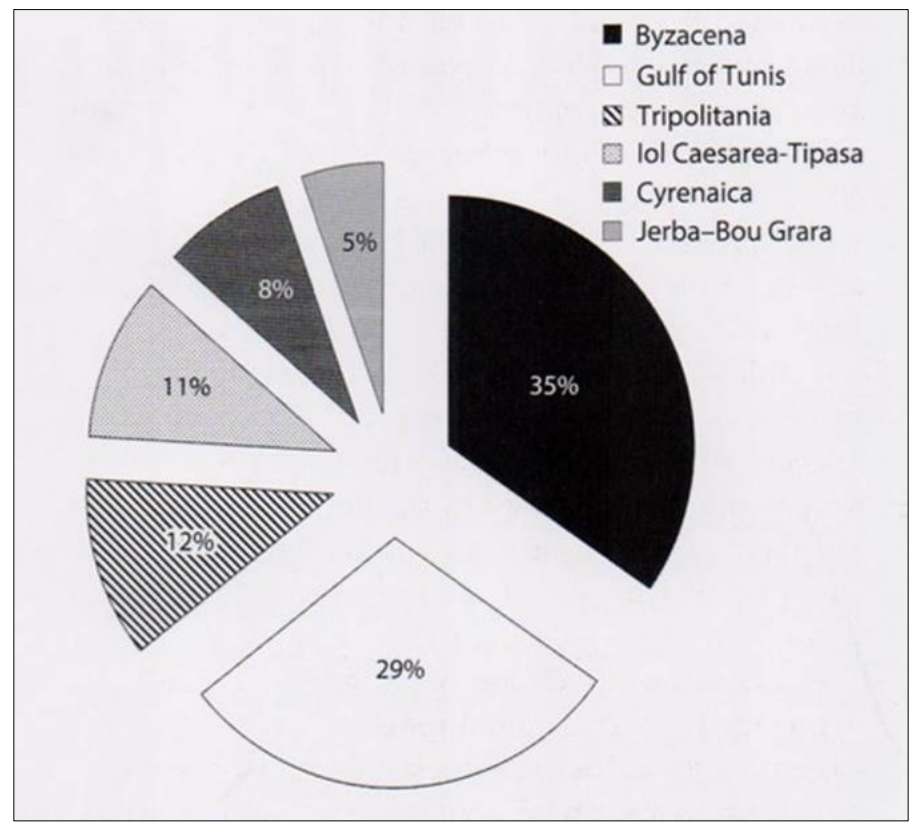

Fig. 12 - Porcentagem do comprimento total de cais na África do Norte por região. Fonte: gráfico modificado de Stone (2014, fig. 8, p. 584).

\section{Considerações finais}

Este texto procurou apresentar questões relevantes sobre o Norte da África centradas no que poderia ser considerado um produto diagnóstico das condições em que se desenvolveram as relações de conectividade e atividades econômicas no Período Romano Tardio: a cerâmica sigillata africana (ARSW). A produção e circulação dessas vasilhas continuam sendo foco de estudos contínuos que remontam à primeira metade do século 20 , com as primeiras tipologias estabelecidas por Frederick Waagé, em 1933, seguido por Nino Lamboglia, em 1948, o qual atribuiu o termo terra sigillata chiara aos produtos feitos em oficinas do Norte da África. Finalmente, John W. Hayes introduziu o termo African Red Slip Ware na literatura arqueológica com a publicação Late Roman Pottery em 1972. Esta primeira fase de estudos, já em 1981, completa-se com a síntese de Andrea Carandini et al. Atlante delle forme ceramiche, I, Ceramica fine romana nel Bacino mediterraneo (medio e tardo impero).

Os estudos mais recentes distinguem-se dos anteriores pela multidisciplinaridade, em especial pelo emprego de métodos arqueométricos. Cabe aqui destacar o domínio absoluto de Michel Bonifay entre os autores que realizam as investigações sobre a ARSW na atualidade. Um leque muito grande de questões emergiu a partir de seus estudos, de forma a permitir avançar novas 
hipóteses e comprovar não apenas a circulação dessas vasilhas no Mediterrâneo, sua associação com ou desvinculação de outros tipos de vasilhas ou produtos de alimentação, como também destacar as necessidades de aprofundamento das pesquisas no interior africano, que deteve uma produção de alimentos de circulação exclusivamente regional acompanhada de vasilhas com tipologias próprias.

Finalmente, no contexto multidisciplinar que tem pautado as pesquisas sobre a produção e circulação da ARSW, são indispensáveis as análises críticas de rotas e fluxos dos navios para o transporte dos itens ao mercado consumidor, assim como de estruturas portuárias pertinentes. Essas permitiram levantar pontos importantes e, ao mesmo tempo, resultados contrastantes que possam explicar o nível em grande escala de produtos exportados das costas africanas.

Em primeiro lugar, o estudo dos fluxos ressalta a necessidade de garantir a carga do navio sempre completa na ida e no retorno ao porto de origem, por questões práticas e econômicas. Por outro lado, os portos analisados são bem conhecidos e referidos na literatura e dependem fortemente do regime sazonal dos ventos, incluindo períodos de cabotagem. Na realidade, na maior parte são portos naturais, com exceção de Cartago, e que têm maior importância em escala local. Neste estudo sobre as rotas de navegação e itinerários no Mediterrâneo Antigo (Arnaud, 2005 apud Bonifay e Tchernia, 2012, p. 326) estão praticamente ausentes vinte e nove portos e conjuntos regionais de portos com estruturas artificiais identificadas e dezesseis prováveis na Mauretânia Tingitana, Mauretânia Cesariense, África Proconsular e Cirenaica. Enfim, é um grande número de estruturas que possibilitaram atender às demandas de forma mais segura e contínua, além de acompanhar a crescente complexidade da ARSW à luz de novas escavações e prospecções ao lado de estudos arqueométricos e outras evidências que possibilitaram o mapeamento da infraestrutura de fabricação regional com o desenvolvimento agrícola e artesanal da África Proconsular/Bizacena. Esta região oferece uma melhor compreensão da dispersão da sigillata dentro de um quadro socioeconômico e sociocultural diacrônico, contribuindo para uma melhor compreensão do funcionamento da economia (ou economias?) romana (Bes e Poblome, 2009, p.67). 
Assim, apenas recentemente foi ultrapassado o descompasso entre o conjunto de pesquisas da ARSW e o das estruturas portuárias que dariam vazão à produção africana, com os resultados dos levantamentos das estruturas artificiais. O conjunto de portos artificiais atende e explica as transformações do modo de comercialização da cerâmica africana no século $\mathrm{V}$, sobretudo o renascimento súbito das oficinas da Bizacena, responsável por $35 \%$ da exportação após mais de um século de hegemonia de Cartago, pelos desembarques não habituais de ânforas de grandes dimensões no mar Negro e pela associação dos carregamentos de ânforas aos de vasilhas cerâmicas. 


\section{REFERÊNCIAS BIBLIOGRÁFICAS}

\section{Fontes Primárias}

Estrabon. Geographie. Paris: Belles Lettres, 2004, Tome XV, Livre XVII, deuxième partie: L'Afrique de l'Atlantique au Golfe de Soloum.

Pline, L’Ancien. Histoire Naturelle. Paris: Forgotten Books, 2017, vol. 5.

Pomponius Mela. Description de la terre. Tome I. Paris: LEN, 2017.

Salluste. La Guerre de Jugurtha. Paris : Belles Lettres, 2002.

Salvius Iulianus. The Digest of Justinian. Philadelphia: University of Pennsylvania, 1985.

\section{Bibliografia Crítica}

Arnaud, Pascal. Les routes de la navigation antique. Itinéraires en Méditerranée. Paris, Errance, 2005.

Bes, Philip; Poblome, Jeroen. African red slip ware on the move: the effect of Bonifay's Etudes for the Roman East. Journal of Roman Archaeology, vol. 22, 2009, p. 65-75.

Bonifay, Michel. La céramique africaine, un indice du développement économique? AnTar, 11, 2003, p. 113-128.

Études sur la Céramique Romaine Tardive d'Afrique. BAR International Series 1301. Oxford: Archaeopress, 2004.

Observations sur la diffusion des céramiques africaines en Méditerranée orientale durant l'Antiquité tardive. In: Baratte, F. et al. (eds) Mélanges Jean-Pierre Sodini (Travaux et Mémoires, 15). Paris: Collège de France, 2005, p. 565-581.

Ceramic production in Africa during Late Antiquity: Continuity and change. In: Lavan, Luke; Zanini, Enrico; Sarantis, Alexander (eds) Technology in Transition A.D. 300-650. Leiden/Boston: Brill, 2007, p. 143-158.

Production et diffusion des céramiques africaines durant l'antiquité tardive. In: Attoui, Redha (ed.) When Did Antiquity End? Archaeological Case Studies in Three Continents. Proceedings of an International Seminar Held at the University of Trento on April 29-30, 2005 on Late Antique Societies, Religion, Pottery and Trade in Germania, Northern Africa, Greece and Asia Minor. Oxford: BAR International Series, 2011, p. 15-30.

. Africa: patterns of consumption in coastal regions versus inland regions. The ceramic evidence (300-700 A.D.). In: Lavan, L. (ed.) Local Economies? Production and Exchange of Inland Regions in Late Antiquity. (Late Antique Archaeology 10) Leiden: Koninklijke Brill NV, 2013, p. 529-566.

. Céramique africaine et imitations: où, quand, pourquoi? In: Morais, R.; Fernandez, A.; Sousa, M.J. (eds) As Produções Cerâmicas de Imitação na Hispania. Monografias Ex Officina Hispana II, Tomo I, 2014, p. 75-91. 
Bonifay, Michel; Capelli, Claudio (avec la collaboration de Carmela Franco, Victoria Leitch, Laurent Riccardi et Piero Berni Millet). Les Thermes du Levant à Leptis Magna: quatre contexts céramiques des IIIe et IVe siècles. In: Griesheimer, Marc; Gascou, Jacques (eds) Antiquités Africaines. Paris: CNRS Éditions, 2013, p. 67-150.

Bonifay, Michel; Tchernia, André. Les réseaux de la céramique africaine (IER-VE siècles). In: Keay, Simon (ed.) Rome. Portus and the Mediterranean. Archaeological Monographs of The British School at Rome. Rome: The British School at Rome, 2012, p. 315-333.

Capelli, Claudio; Bonifay, Michel. Archéometrie et archéologie des céramiques Africaines: une approche pluridisciplinaire, 2. Nouvelles Données sur la Céramique Culinaire et les Amphores. In: Poulo-Papadimitriou, Natalia; Nodarou, Eleni; Kilikoglou, Vassilis (eds) $L R C W$ 4. Late Roman Coarse Wares, Cooking Wares and Amphorae in the Mediterranean. Archaeology and archaeometry. The Mediterranean: a market without frontiers. Volume 1. BAR International Series 2616 (I). Oxford: Information Press, 2014, p. 235-253.

Carandini, Andrea. Pottery and the African economy. In: Garnsey, Peter; Hopkins, Keith; Whittaker, R. (eds) Trade in Ancient Economy. London: University of California Press, 1983, p. 45-62

Carandini, A.; Anselmo, L. Pavolini, C.; Sagui, L.; Tortorella, S.; Tortorici, E. Atlante delle Forme Ceramiche, I, Ceramica Fine Romana nel Bacino Mediterraneo (Medio e Tardo Impero), Enciclopedia dell'Arte Antica. Roma: Treccani, 1981.

Cau, Miguel Ángel; Reynolds, Paul; Bonifay. Michel. An initiative for the revision of Late Roman fine wares in the Mediterranean (c. AD 200-700): The Barcelona ICREA/ESF Workshop. LRFW Working Group, 2012, p. 1-13.

Clay, T. Carthage et son commerce dans l'Antiquité Tardive. In: Afrique du Nord Antique et Médievale, Spectacles, Vie Portuaire, Religions. Actes du Ve Colloque international sur l'Histoire et l'Archéologie de l'Afrique du Nord (Avignon, 9-13 avril 1990). Paris, 1992, p. 349-359.

Fleming, Maria Isabel D’A. Lucernas norte-africanas tardias de terra sigillata: curadoria de coleções museológicas e pesquisas arqueológicas. Heródoto, 2017, no prelo.

Fulford, M. G. The red-slipped wares. In: Fulford, M. G.; Peacock, D. P. S. Excavations at Carthage: The British Mission I, 2: The Avenue du Président Habib Bourguiba, Salammbo: The Pottery and Other Ceramic Objects From the Site. Sheffield, 1984, p. 48-115.

Hayes, John W. Late Roman Pottery. London: British School at Rome, 1972.

Humprhey, J.H. (Ed.) Studies on Roman Pottery of the Provinces of Africa Proconsularis and Byzacena (Tunisia). Hommage à Michel Bonifay. Portsmouth: Rhode Island, 2009.

Lamboglia, Nino. Nuove osservazioni sulla "Terra Sigillata Chiara" (Tipi A e B). Rivista di Studi Liguri, 24, 3-4, 1958, p. 257-330.

Mocanu, Marian. Notes on the "African Red Slip Ware" ceramics in Scythia Minor. Studia Antiquae et Archaeologica, 18, 1, 2012, p. 319-340. 
Panella, Clementina. Merci e scambi nel Mediterraneo tardoantico. In: Storia di Roma III, 2. Turim: Einaudi, 1993, p. 614-697.

Pieri, D. Le Commerce du Vin Oriental à l'Époque Byzantine (Ve-VIIe Siècle) (Bibliothèque Archéologique et d'Historique 174), Paris, 2005.

Stone, D. L. 2014, Africa in the Roman Empire: connectivity, the economy, and artificial port structures. $A J A, 118,2014$, p. 565-600.

Waagé, Frederick O. The Roman and Byzantine Pottery. Hesperia 2, 1933, p. 279-328. 